\title{
KARTU ELLIPS DI SUMBU X DAN Y MATERI IRISAN KERUCUT SEBAGAI MEDIA PEMBELAJARAN MATEMATIKA PEMINATAN SISWA KELAS XI MADRASAH ALIYAH NEGERI BINJAI
}

\author{
Siti Rohani \\ Surel: sitir5774@gmail.com
}

\begin{abstract}
Innovation in the media as a learning tool can also be used to improve the quality of education in accordance with the talents and abilities of teachers as educators and students as students. Therefore, the author tries to make a learning tool as a medium for learning mathematics with specialization in teaching and learning activities in the classroom with the aim of increasing students' understanding of the Cone Slice material about Ellipses on the $X$ and $Y$ axes, this can be seen from the average value of the first cycle the results of the first daily examination of 83.34 and the second daily examination of 85.24 and the second cycle the results of the third daily examination of 87.42 and the fourth daily examination of 91.37 with a KKM score of 85, as well as to increase student activity, this can seen from the average student attendance of $88 \%$ to $90 \%$ in the first cycle, and the average student attendance of $95 \%$ to $100 \%$ in the second cycle, which means that students are very happy in learning mathematics with specialization, especially material about ellipses.
\end{abstract}

Keywords : Ellipse Card on X and Y Axis Cone Slice Material, Specialization Mathematics Learning Media, Inovation

\begin{abstract}
ABSTRAK
Inovasi pada media sebagai alat pembelajaran dapat juga digunakan untuk meningkatkan mutu pendidikan yang sesuai dengan bakat dan kemampun guru sebagai pendidik dan siswa sebagai peserta didik. Oleh karenanya, penulis mencoba membuat suatu alat pembelajaran sebagai media pembelajaran matematika peminatan dalam kegiatan proses belajar mengajar di kelas mempunyai tujuan untuk meningkatkan pemahaman siswa pada materi Irisan Kerucut tentang Ellips di sumbu X dan Y, hal ini dapat dilihat dari nilai rata-rata siklus pertama hasil ujian harian pertama sebesar 83,34 dan ujian harian kedua sebesar 85,24 dan siklus kedua hasil ujian harian ketiga sebesar 87,42 dan ujian harian keempat sebesar 91,37 dengan nilai KKM sebesar 85, serta untuk meningkatkan aktivitas siswa, hal ini dapat dilihat dari rata-rata kehadiran siswa $88 \%$ menjadi $90 \%$ pada siklus pertama, dan rata-rata kehadiran siswa 95\% menjadi 100\% pada siklus kedua, yang artinya siswa sangat senang dalam belajar matematika peminatan terutama materi tentang Ellips.
\end{abstract}

Kata Kunci : Kartu Ellips di sumbu X dan Y Materi Irisan Kerucut, Media Pembelajaran Matematika Peminatan, Inovasi

\section{PENDAHULUAN}

Inovasi pada media sebagai alat pembelajaran dapat juga diguna kan untuk meningkatkan mutu pendidikan yang sesuai dengan bakat dan kemampun guru sebagai pendidik dan siswa sebagai peserta didik. Apalagi saat sekarang ini masa pandemik, belajar tidak dapat dilaku kan dengan cara tatap muka, melain kan dengan Daring. Dimana salah satu pelajaran yang dirasa sulit oleh siswa adalah pelajaran matematika. Pelajaran ini di mata siswa adalah suatu pelajaran yang sangat sulit, membosankan dan kurang me nyenangkan. Seorang pendidik berusaha agar pembelajaran secara 
Daring dapat dilakukan secara aktif, baik keaktivan itu berasal dari guru, maupun berasal dari siswa itu sendiri. Bagaimana cara seorang pendidik mengajarkan pelajaran matematika pada materi irisan kerucut (lingkaran, parabola, ellips, dan hiperbola) yang salah satunya tentang Ellips dapat difahami oleh siswa.

Tujuan yang ingin dicapai oleh penulis adalah Untuk menge- tahui pembuatan Kartu Ellips di Sumbu X dan Y Materi Irisan Kerucut Sebagai Media Pembelajaran Matematika Peminatan dapat meningkatkan pemahaman dan aktivitas Siswa Kelas XI Madrasah Aliyah Negeri Binjai Semester Ganjil tahun Pelajaran 2020/2021.

\section{METODE PENELITIAN}

Penelitian ini dilaksanakan di kelas XI Madrasah Aliyah Negeri Binjai yang beralamat di jalan Pekan Baru Nomor 1A Kelurahan Rambung Barat Binjai. Jumlah siswa kelas XI Madrasah Aliyah Negeri Binjai Semester Ganjil Tahun Pelajaran 2020/2021 adalah 38 siswa, jumlah siswa laki-laki 23 orang dan siswa perempuan 15 orang. Pelaksanaan penelitian ini dilaksanakan selama tiga bulan yaitu bulan Oktober, November dan Desember tahun 2020, dan terdiri dari dua siklus.

Pelaksanaan penelitian siklus pertama dimulai bulan Oktober tahun 2020, dilakukan beberapa rincian sebagai berikut;

Perencanaan pertama, guru mem persiapkan RPP dan bahan ajar yang berkaitan dengan materi Irisan Kerucut (Lingkaran, Parabola, Ellips, dan Hiperbola) yang salah satunya tentang Ellips.

Tindakan pertama, untuk memudah kan guru dalam proses kegiatan belajar mengajar beberapa kali pertemuan, maka guru mem persiapkan kelompok diskusi sebanyak jumlah siswa, dimana masing-masing siswa mendapat satu tugas yaitu cara menggambar Ellips. Selanjutya guru menjelaskan secara Daring materi Irisan Kerucut tentang Ellips.

Observasi/Pengamatan pertama, Observasi dilakukan oleh observer (pengamat) yaitu peneliti dan teman sejawat (guru matematika yang ikut terlibat dalam penelitian) untuk melihat secara Daring, dan menilai aktivitas siswa selama pembelajaran matematika peminatan materi Irisan Kerucut tentang Ellips di sumbu X dan Y. Sampai dimana siswa memahami materi tersebut, dan bagaimana aktivitas siswa selama siswa mengikuti kegiatan pem- belajaran matematika peminatan ini.

Refleksi (Reflection) pertama, Pada tahap refleksi ini dilakukan analisis hasil belajar (pre test 1) yaitu ujian harian pertama dan kedua setelah guru menjelaskan materi Irisan Kerucut tentang Ellips di sumbu X dan Y, baik pemahaman penggunaan rumus Ellips maupun cara meng gambarkannya pada sumbu koordinat kartesius.

Penelitian berikut siklus kedua dimulai pada bulan November dan 
Desember 2020, dan dilakukan beberapa rincian sebagai berikut ;

Perencanaan kedua, pada pertemuan berikutnya guru bersikap memberikan gambaran cara membuat kartu Ellips sebagai berikut: Proses pembuatan kartu Ellips di sumbu X dan Y sebagai media pembelajaran metematika ini dilaksanakan di Madrasah Aliyah Negeri Binjai yang dibuat oleh siswa secara manual yaitu ditulis di kertas karton, yang selanjutnya dapat dibuat secara rapi dengan menggunakan komputer, yang dibimbing oleh penulis sebagai guru matematika dan temen sejawat guru matematika serta dipraktekkan ke para siswa siswi di rumah. Pembuatan kartu Ellips di Sumbu X dan Y ini dilakukan setelah proses pembelajaran matematika tentang persamaan dan letak gambar Ellips di sumbu $\mathrm{X}$ dan $\mathrm{Y}$ telah diajarkan pada siswa. Setelah siswa siswi memahami materi persamaan dan letak gambar Ellips di sumbu $X$ dan $\mathrm{Y}$ barulah guru mengarahkan untuk membuat kartu matematika agar lebih mudah mengingatnya.

Tindakan kedua, guru membimbing siswa cara membuat kartu Ellips sampai kartu Ellips tersebut terbentuk, yaitu Satu set kartu ini masing-masing jumlahnya 81 lembar, yang diperoleh dari peng hubungan antara tiap-tiap tujuh macam gambar dengan tiap-tiap tujuh macam rumus dan syarat. Berikut ini contoh pembuatan kartu dengan kompetensi dasarnya: penggunaan rumus dan gambar Ellips di sumbu X dan Y. Dan Indikatornya: meng- hubungkan antara tiap-tiap tujuh macam penggunaan rumus dengan tiap-tiap tujuh macam gambar Ellips di sumbu X dan Y. Pemetaan pembuatan kartu Ellips di sumbu $X$ dan Y, cara pembuatannya sebagai berikut:

Gambar 1. Letak gambar Ellips di Sumbu X pada sumbu koordinat

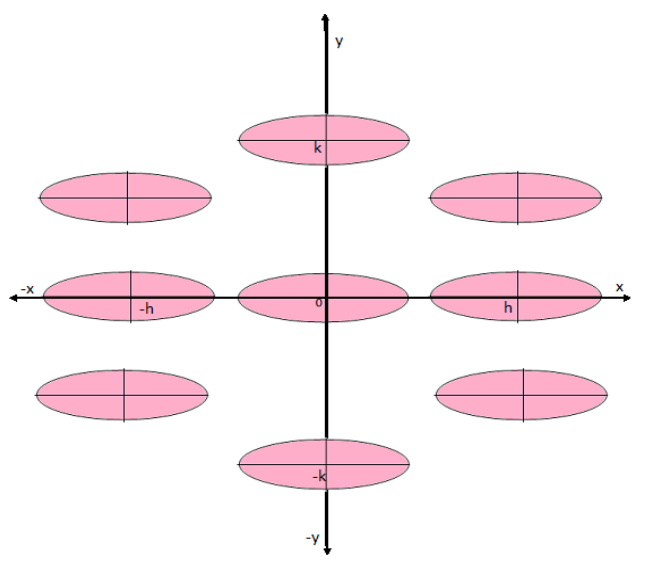

Gambar 2. Letak gambar Ellips di sumbu Y pada sumbu koordinat

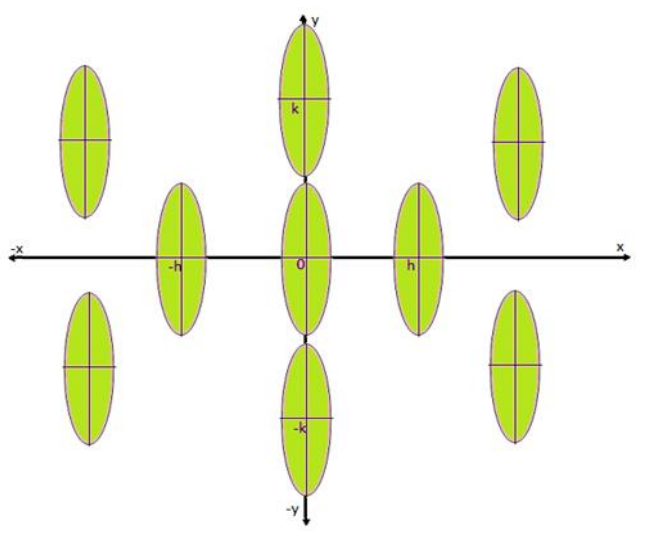


Siti Rohani : Kartu Ellips di Sumbu X dan Y ...

Gambar 3. Menghubungkan tiap gambar Ellips dengan rumus Ellips di sumbu X

\begin{tabular}{|c|c|c|}
\hline$\underbrace{r}_{1}$ & & $\begin{array}{l}\frac{x^{2}}{a^{2}}+\frac{y^{2}}{b^{2}}=1 \\
\text { Pusat }(\mathbf{0}, \mathbf{0}) \\
\text { Puncak }( \pm \mathbf{a}, \mathbf{0}) \\
\text { Fokus }( \pm \mathbf{c}, \mathbf{0})\end{array}$ \\
\hline$b^{-x}$ & & $\begin{array}{l}\frac{(x-h)^{2}}{a^{2}}+\frac{(y-k)^{2}}{b^{2}}=1 \\
\text { Pusat }(\mathbf{h}, \mathbf{k}) \\
\text { Puncak }(\mathbf{h} \pm \mathbf{a}, \mathbf{k}) \\
\text { Fokus }(\mathbf{h} \pm \mathbf{c}, \mathbf{k})\end{array}$ \\
\hline 2 & & $\begin{array}{l}\frac{(x+h)^{2}}{a^{2}}+\frac{(y-k)^{2}}{b^{2}}=1 \\
\text { Pusat }(-\mathbf{h}, \mathbf{k}) \\
\text { Puncak }(-\mathbf{h} \pm \mathbf{a}, \mathbf{k}) \\
\text { Fokus }(-\mathbf{h} \pm \mathbf{c}, \mathbf{k})\end{array}$ \\
\hline$-r$ & & $\begin{array}{l}\frac{(x-h)^{2}}{a^{2}}+\frac{y^{2}}{b^{2}}=1 \\
\text { Pusat }(\mathbf{h}, \mathbf{0}) \\
\text { Puncak }(\mathbf{h} \pm \mathbf{a}, \mathbf{0}) \\
\text { Fokus }(\mathbf{h} \pm \mathbf{c}, \mathbf{0})\end{array}$ \\
\hline & & $\begin{array}{l}\frac{(x+h)^{2}}{a^{2}}+\frac{y^{2}}{b^{2}}=1 \\
\text { Pusat }(-\mathbf{h}, \mathbf{0}) \\
\text { Puncak }(-\mathbf{h} \pm \mathbf{a}, \mathbf{0}) \\
\text { Fokus }(-\mathbf{h} \pm \mathbf{c}, \mathbf{0})\end{array}$ \\
\hline$\gamma$ & 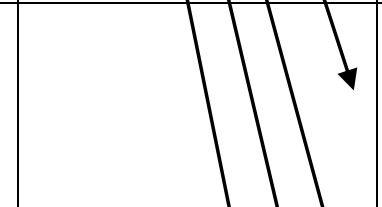 & $\begin{array}{l}\frac{(x+h)^{2}}{a^{2}}+\frac{(y+k)^{2}}{b^{2}}=1 \\
\text { Pusat }(-\mathbf{h},-\mathbf{k}) \\
\text { Puncak }(-\mathbf{h} \pm \mathbf{a},-\mathbf{k}) \\
\text { Fokus }(-\mathbf{h} \pm \mathbf{c},-\mathbf{k})\end{array}$ \\
\hline$\gamma_{-r}^{k}$ & & $\begin{array}{l}\frac{(x-h)^{2}}{a^{2}}+\frac{(y+k)^{2}}{b^{2}}=1 \\
\text { Pusat }(\mathbf{h},-\mathbf{k}) \\
\text { Puncak }(\mathbf{h} \pm \mathbf{a},-\mathbf{- k}) \\
\text { Fokus }(\mathbf{h} \pm \mathbf{c},-\mathbf{k})\end{array}$ \\
\hline$\left.\right|_{-x}$ & $\downarrow$ & $\begin{array}{l}\frac{x^{2}}{a^{2}}+\frac{(y-k)^{2}}{b^{2}}=1 \\
\text { Pusat }(\mathbf{0 , k}) \\
\text { Puncak }( \pm \mathbf{a}, \mathbf{k}) \\
\text { Fokus }( \pm \mathbf{c}, \mathbf{k})\end{array}$ \\
\hline \begin{tabular}{l|l}
$x$ & \\
& \\
$-r$
\end{tabular} & $\downarrow$ & $\begin{array}{l}\frac{x^{2}}{a^{2}}+\frac{(y+k)^{2}}{b^{2}}=1 \\
\text { Pusat }(\mathbf{0},-\mathbf{k}) \\
\text { Puncak }( \pm \mathbf{a},-\mathbf{- k}) \\
\text { Fokus }( \pm \mathbf{c},-\mathbf{k})\end{array}$ \\
\hline
\end{tabular}


Gambar 4. Menghubungkan tiap gambar Ellips dengan rumus Ellips di sumbu Y

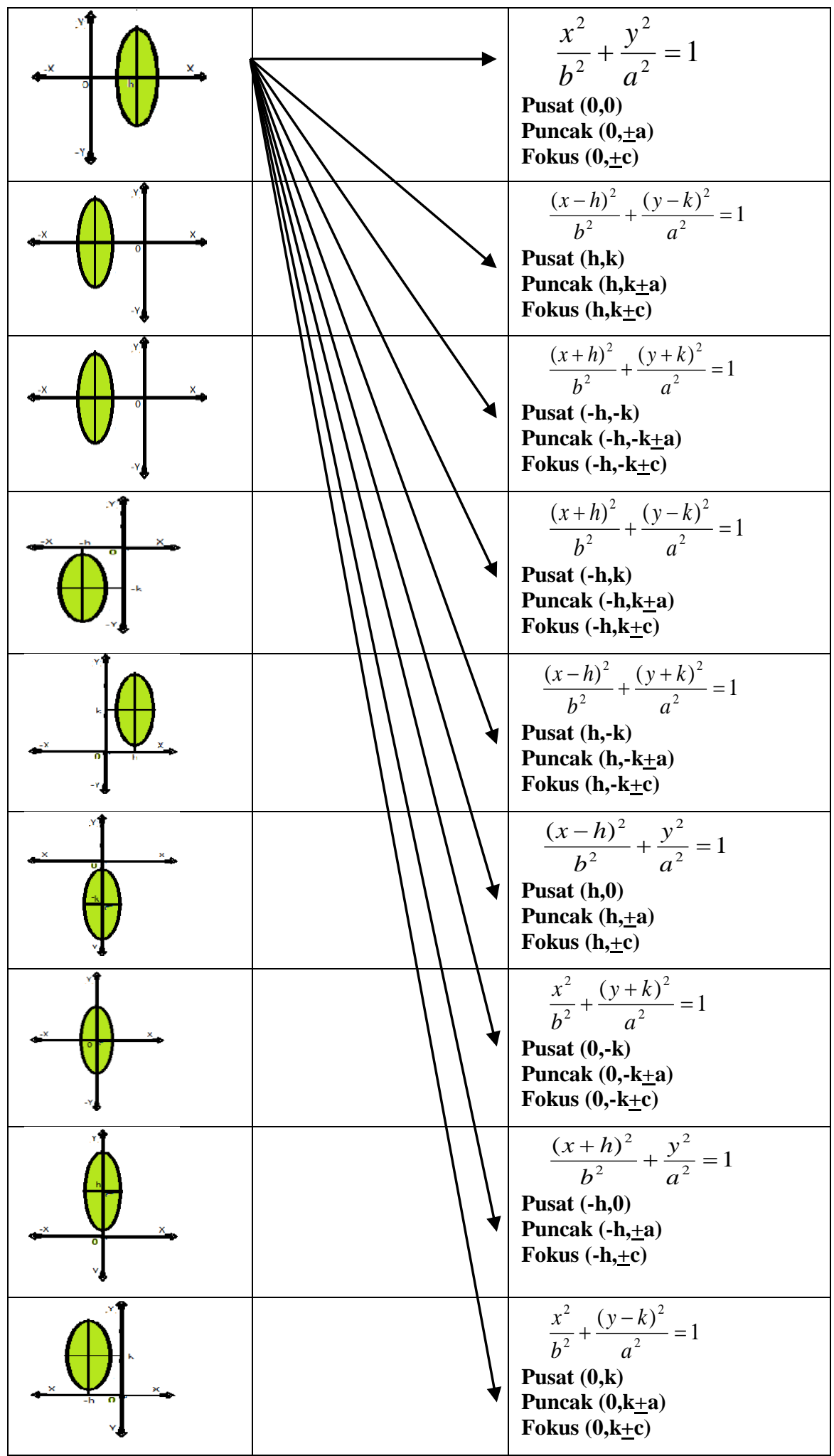


Observasi / Pengamatan kedua, untuk mengetahui sejauhmana siswa dapat membuat kartu Ellips di sumbu $\mathrm{X}$ maupun Y. Hasil dari pembuatan kartu Ellips tersebut dicoba untuk dimainkan secara sendiri di rumah, dan dilanjutkan dengan cara ber kelompok. Guru mengajarkan ke siswa bagaimana cara bermain kartu Ellips di sumbu X maupun Y. Di sini dicoba beberapa macam cara memainkan kartu, sebagai berikut: Cara permainan pertama, dimainkan oleh 7 orang pemain, Bagikan kartu Ellips yang khusus dibuat untuk permainan ini, sampai habis terbagi untuk masing -masing pemain. Pemain pertama meletakkan sebuah kartu di meja (undilah siapa yang jadi pemain pertama). Dengan urutan sesuai arah jarum jam para pemain menjatuhkan satu kartu pada setiap gilirannya. Pemain yang tidak memiliki sambungan kartu tersebut (Jika pemain tidak bisa "jalan" maka ia kehilangan satu giliran), maka ia akan kehilangan permainan, dan langsung dilanjutkan dengan pemain yang berikutnya. Nilai setiap gambar ellips pada kartu yang dipasangkan (dijatuhkan) disesuaikan dengan rumus pada kartu yang ada (yang dijatuhkan) sampai pemain tidak memiliki kartu lagi (Hubungkan setiap gambar ellips dengan rumus yang sesuai dengan gambar yang ada pada kartu). Pemenangnya ialah yang pertama-tama dapat menghabiskan kartunya.

Cara permainan kedua, dimainkan oleh 2, 3, 4, 5, 6 dan 7 orang pemain. Bagikan kartu Ellips yang khusus dibuat untuk permainan ini, sebanyak empat kartu terbagi untuk masing-masing pemain. Tinggalkan sisa kartu yang ada, dan dimulai dengan meletakkan satu kartu dari kartu yang tersisa. Pemain pertama menyambung dari sebuah kartu yang telah diletak kan di meja (undilah siapa yang jadi pemain pertama). Dengan urutan sesuai arah jarum jam para pemain menjatuhkan satu kartu pada setiap gilirannya. Pemain yang tidak memiliki sambungan kartu tersebut (Jika pemain tidak bisa "jalan"), maka ia mencangkul dari sisa kartu yang ada sampai menemukan sambungan nya, dan langsung dilanjutkan dengan pemain yang berikutnya. Nilai setiap gambar ellips pada kartu yang dipasangkan (dijatuhkan) disesuaikan dengan rumus pada kartu yang ada (yang dijatuhkan) sampai pemain tidak memiliki kartu lagi (Hubungkan setiap gambar ellips dengan rumus yang sesuai dengan gambar yang ada pada kartu). Pemenangnya ialah yang pertama-tama dapat menghabiskan kartunya.

Gambar 5. Contoh gambar kartu sumbu X

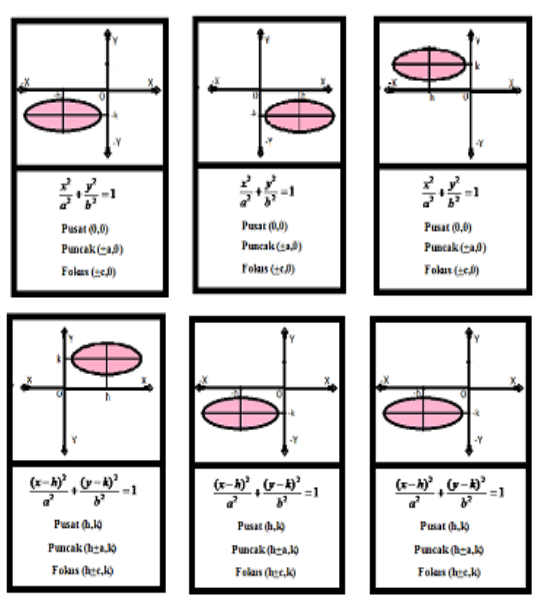


Gambar 6. Contoh cara bermain kartu sumbu X

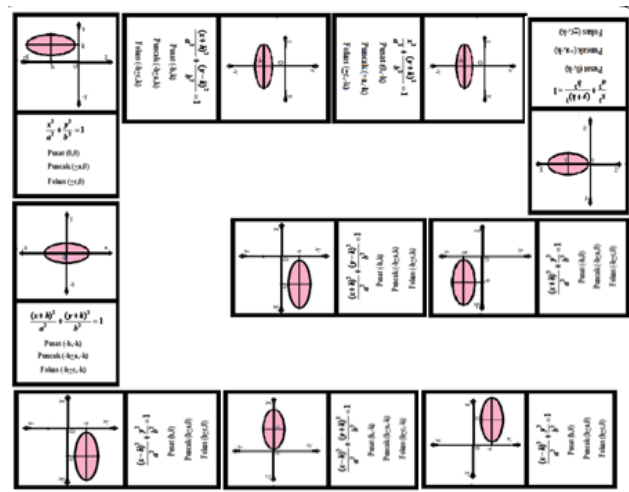

Gambar 7. Contoh gambar kartu sumbu Y
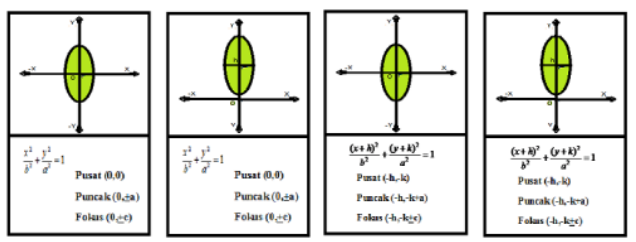

Gambar 8. Contoh cara bermain kartu sumbu Y

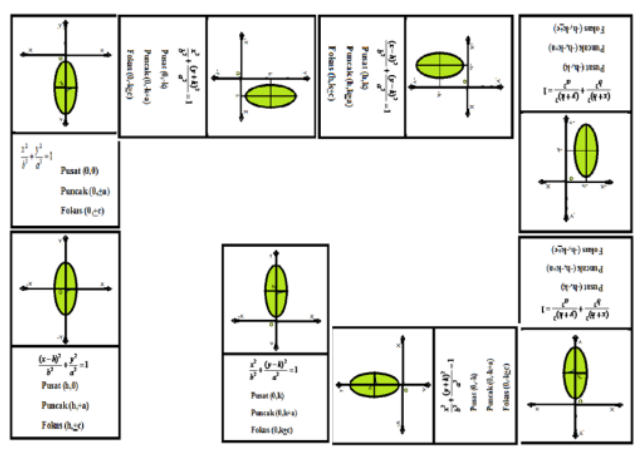

Refleksi (Reflection) kedua, Pada tahap refleksi ini dilakukan analisis hasil belajar (post test 2) yaitu ujian harian ketiga dan keempat setelah guru menjelaskan cara bermain dengan baik dan menggunakan waktu yang tepat disaat bermain kartu, dan mengaplikasikannya ke contoh soal yang berisikan materi Irisan Kerucut tentang Ellips di sumbu X dan Y, serta pemahaman penggunaan rumus Ellips maupun cara menggambarkan nya pada sumbu koordinat kartesius.
Begitu juga analisis hasil observasi aktivitas siswa terutama kehadiran siswa dalam mengikuti kegiatan pembelajaran matematika peminatan ini. Hasilnya ditulis dibuku catatan singkat, yang akan digunakan sebagai gambaran kekurangan yang belum tuntas yang akan diperbaiki pada tindakan lanjutan berikutnya. Jika belum tuntas maka akan dilanjutkan pada siklus ketiga atau siklus berikutnya. Namun pada penelitian tindakan kelas ini di siklus kedua siswa sudah dianggap memahami materi Irisan Kerucut tentang Ellips di sumbu $\mathrm{X}$ dan $\mathrm{Y}$, baik penggunaan rumus Ellips, maupun menggambar Ellips pada sumbu koordinat kartesius, maka penelitian tindakan kelas (PTK) yang dilaksanakan selama dua siklus ini tidak dilanjutkan lagi.

\section{HASIL PENELITIAN DAN PEMBAHASAN}

Semua kartu Ellips sumbu $\mathrm{X}$ maupun sumbu Y, jika dimainkan dengan teliti dan kartu semuanya habis tersusun, maka akan mem bentuk suatu lingkaran yang dapat dilihat pada gambar berikut ini:

\section{Gambar 9. Permainan Kartu Ellips Secara Berkelompok}

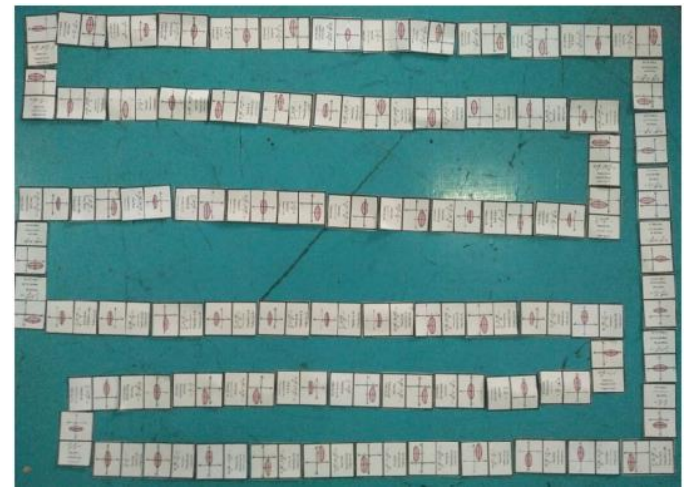

Permainan kartu Ellips ini dapat dilakukan berkelompok, dan dinilai tiap-tiap siswa oleh guru. Hal 
Siti Rohani : Kartu Ellips di Sumbu X dan Y ...

yang dinilai selain pemahaman siswa terhadap materi Irisan Kerucut tentang Ellips di sumbu $\mathrm{X}$ dan $\mathrm{Y}$, juga keaktifan siswa selama mengikuti penelitian tindakan kelas (PTK) yang dilaksanakan dua siklus. Setelah di lakukannya beberapa kali permainan kartu Ellips tersebut, guru memberi kan latihan soal berbentuk ujian harian pertama, kedua, ketiga dan keempat, sebagai pengamatan atau observasi dari hasil pembuatan kartu Ellips. Refleksi yang dihasilkan dari hasil ujian harian pertama, kedua, ketiga dan keempat menunjukkan peningkatan rata-rata nilai hasil belajar untuk materi Irisan Kerucut tentang Ellips di sumbu X dan Y. Nilai ini dapat dilihat pada tabel:

Tabel 1. Kegiatan Penelitian Tindakan Kelas Pada Siklus Pertama dan Kedua Rangkuman Hasil Ujian Harian Matematika Peminatan Tentang Ellips Siswa Kelas XI Madrasah Aliyah Negeri Binjai Semester Ganjil Tahun Pelajaran 2020/2021

\begin{tabular}{|c|c|c|c|c|c|}
\hline \multirow[b]{2}{*}{$\mathrm{NO}$} & \multirow[b]{2}{*}{ NAMA SISWA } & \multicolumn{4}{|c|}{ Nilai Hasil Ujian Harian Tentang Ellips } \\
\hline & & Ujian 1 & Ujian 2 & Ujian 3 & Ujian 4 \\
\hline 1 & Siswa ke 1 & 80 & 82 & 85 & 89 \\
\hline 2 & Siswa ke 2 & 80 & 82 & 85 & 89 \\
\hline 3 & Siswa ke 3 & 83 & 85 & 87 & 91 \\
\hline 4 & Siswa ke 4 & 85 & 87 & 89 & 93 \\
\hline 5 & Siswa ke 5 & 85 & 87 & 89 & 93 \\
\hline 6 & Siswa ke 6 & 82 & 84 & 86 & 90 \\
\hline 7 & Siswa ke 7 & 90 & 91 & 92 & 96 \\
\hline 8 & Siswa ke 8 & 82 & 84 & 86 & 90 \\
\hline 9 & Siswa ke 9 & 88 & 89 & 90 & 94 \\
\hline 10 & Siswa ke 10 & 88 & 89 & 90 & 94 \\
\hline 11 & Siswa ke 11 & 82 & 84 & 86 & 90 \\
\hline 12 & Siswa ke 12 & 83 & 85 & 87 & 91 \\
\hline 13 & Siswa ke 13 & 82 & 84 & 86 & 90 \\
\hline 14 & Siswa ke 14 & 80 & 82 & 85 & 89 \\
\hline 15 & Siswa ke 15 & 80 & 82 & 85 & 89 \\
\hline 16 & Siswa ke 16 & 83 & 85 & 87 & 91 \\
\hline 17 & Siswa ke 17 & 83 & 85 & 87 & 91 \\
\hline 18 & Siswa ke 18 & 80 & 82 & 85 & 89 \\
\hline 19 & Siswa ke 19 & 89 & 90 & 91 & 95 \\
\hline 20 & Siswa ke 20 & 84 & 86 & 88 & 92 \\
\hline 21 & Siswa ke 21 & 83 & 85 & 87 & 91 \\
\hline 22 & Siswa ke 22 & 85 & 87 & 89 & 93 \\
\hline 23 & Siswa ke 23 & 84 & 86 & 88 & 92 \\
\hline 24 & Siswa ke 24 & 84 & 86 & 88 & 92 \\
\hline 25 & Siswa ke 25 & 84 & 86 & 88 & 92 \\
\hline 26 & Siswa ke 26 & 91 & 92 & 94 & 98 \\
\hline 27 & Siswa ke 27 & 84 & 86 & 88 & 92 \\
\hline 28 & Siswa ke 28 & 80 & 82 & 85 & 89 \\
\hline 29 & Siswa ke 29 & 82 & 84 & 86 & 90 \\
\hline 30 & Siswa ke 30 & 78 & 81 & 85 & 88 \\
\hline 31 & Siswa ke 31 & 80 & 82 & 85 & 89 \\
\hline 32 & Siswa ke 32 & 82 & 84 & 86 & 90 \\
\hline 33 & Siswa ke 33 & 82 & 84 & 86 & 90 \\
\hline 34 & Siswa ke 34 & 78 & 81 & 85 & 88 \\
\hline 35 & Siswa ke 35 & 83 & 85 & 87 & 91 \\
\hline 36 & Siswa ke 36 & 89 & 90 & 92 & 96 \\
\hline 37 & Siswa ke 37 & 85 & 87 & 89 & 93 \\
\hline \multirow[t]{3}{*}{38} & Siswa ke 38 & 84 & 86 & 88 & 92 \\
\hline & Jumlah & 3167 & 3239 & 3322 & 3472 \\
\hline & Rata-Rata & 83,34 & 85,24 & 87,42 & 91,37 \\
\hline
\end{tabular}




\section{Pembahasan}

Hasil dari penelitian tindakan kelas (PTK) ini selama dua siklus diperoleh nilai rata - rata dari ujian harian yang dilakukan selama observasi dapat dibuat dalam bentuk diagram batang sebagai berikut:

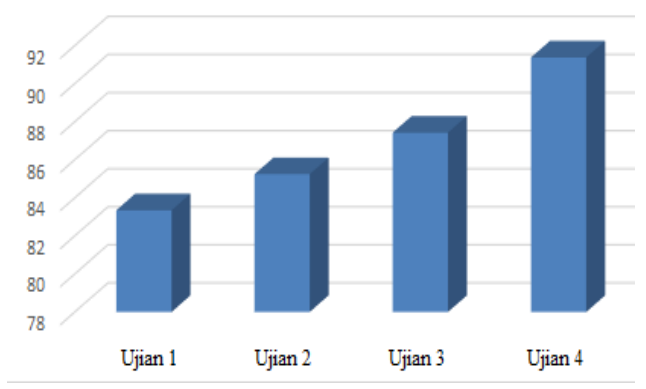

Gambar 10. Diagram Rata-rata Nilai Hasil Ujian Harian Pelajaran Matematika Peminatan Materi Ellips

Berdasarkan gambar diagram batang di atas diperoleh nilai rata-rata siklus pertama hasil ujian harian pertama sebesar 83,34 dan ujian harian kedua sebesar 85,24 dan siklus kedua hasil ujian harian ketiga sebesar 87,42 dan ujian harian keempat sebesar 91,37 dengan nilai KKM sebesar 85. Ini artinya siswa semakin faham dan terdapat peningkatan hasil pembelajaran matematika peminatan materi Irisan Kerucut tentang Ellips di sumbu X dan Y.

Sementara aktivitas siswa pada kegiatan penelitian tindakan kelas (PTK) ini selama dua siklus diperoleh rata-rata dari kehadiran siswa dapat dibuat dalam bentuk diagram batang sebagai berikut:

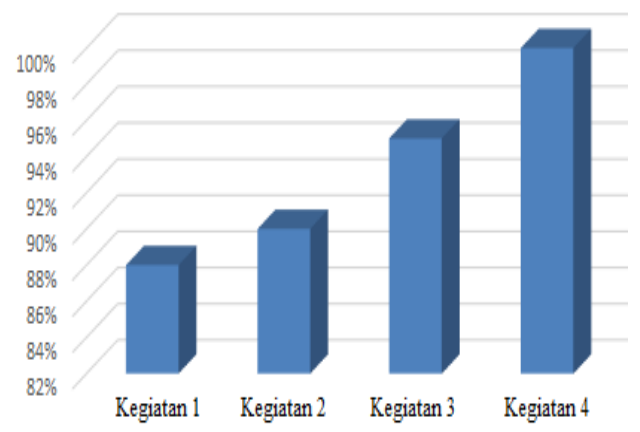

Gambar 11. Diagram Kehadiran Siswa Mengikuti Kegiatan Pembelajaran Matematika Peminatan Materi Ellips

Berdasarkan gambar diagram batang di atas diperoleh nilai rata rata kehadiran siswa $88 \%$ menjadi 90\% pada siklus pertama, dan rata rata kehadiran siswa 95\% menjadi $100 \%$ pada siklus kedua, yang artinya siswa sangat senang dalam belajar matematika terutama materi tentang Ellips.

\section{SIMPULAN}

Berdasarkan beberapa penjelasan sebelumnya penulis menyimpulkan sebagai berikut : Pembuatan Kartu Ellips di Sumbu X dan Y Materi Irisan Kerucut Sebagai Media Pembelajaran Matematika Peminatan dapat meningkatkan pemahaman Siswa Kelas XI Madrasah Aliyah Negeri Binjai Semester Ganjil tahun Pelajaran 2020/2021, hal ini dapat dilihat dari nilai rata - rata siklus pertama hasil ujian harian pertama sebesar 83,34 dan ujian harian kedua sebesar 85,24 dan siklus kedua hasil ujian harian ketiga sebesar 87,42 dan ujian harian keempat sebesar 91,37 dengan nilai KKM sebesar 85, serta untuk meningkatkan aktivitas siswa, hal ini dapat dilihat dari rata - rata kehadiran siswa $88 \%$ menjadi $90 \%$ pada siklus pertama, dan rata - rata kehadiran siswa $95 \%$ menjadi $100 \%$ pada siklus kedua, yang artinya siswa 
Siti Rohani : Kartu Ellips di Sumbu X dan Y ...

sangat senang dalam belajar matematika terutama materi tentang Ellips.

\section{DAFTAR RUJUKAN}

Akbar, S. 2013. Instrumen Perangkat Pembelajaran. Bandung: Remaja Rosdakarya.

Ahmadi, A., dan Supriyono, W. 1993. Psikologi Belajar. Jakarta: Raja Grafindo Persada.

Arikunto, S. 2003. Prosedur Penelitian, Suatu Pendekatan Praktek. Jakarta : Rineka Cipta.
Hamdani. 2011. Strategi Belajar Mengajar. Bandung: Pustaka Setia.

H. Sigit Suprijanto dkk. 2012. Matematika SMA Kelas XI. Jakarta: Yudistira

Slameto. 2010. Belajar dan Faktorfaktor yang Mempengaruhi. Jakarta: Rineka Cipta.

Sardiman, AM. 2011. Interaksi dan Motivasi Belajar Mengajar. Jakarta: Rajawali Pers. 